\title{
Surgical Intervention for Instability of the Craniovertebral Junction
}

\author{
Masakazu TAKAYASU, ${ }^{1}$ Masahiro AOYAMA, ${ }^{1}$ Masahiro JOKO, ${ }^{1}$ \\ and Mikinobu TAKEUCHI ${ }^{1}$
}

${ }^{1}$ Department of Neurological Surgery, Aichi Medical University, Nagakute, Aichi

\begin{abstract}
Surgical approaches for stabilizing the craniovertebral junction (CVJ) are classified as either anterior or posterior approaches. Among the anterior approaches, the established method is anterior odontoid screw fixation. Posterior approaches are classified as either atlanto-axial fixation or occipito-cervical (O-C) fixation. Spinal instrumentation using anchor screws and rods has become a popular method for posterior cervical fixation. Because this method achieves greater stability and higher success rates for fusion without the risk of sublaminar wiring, it has become a substitute for previous methods that used bone grafting and wiring. Several types of anchor screws are available, including C1/2 transarticular, C1 lateral mass, C2 pedicle, and translaminar screws. Appropriate anchor screws should be selected according to characteristics such as technical feasibility, safety, and strength. With these stronger anchor screws, shorter fixation has become possible. The present review discusses the current status of surgical interventions for stabilizing the CVJ.
\end{abstract}

Key words: craniovertebral junction, fixation, screw, spinal instrumentation

\section{Introduction}

The craniovertebral junction (CVJ) has complicated anatomical and functional properties that allow complex mobility. It consists of multiple joints, such as the atlanto-occipital and atlanto-axial joints, which function as a mobile unit allowing flexion, extension, and a wide range of rotation. Ligaments and muscles play an important role in maintaining the stability of this unit. As a result, the stability of the CVJ is vulnerable to trauma and other pathologies. It also encloses important neurological and vascular organs, such as the medulla oblongata, spinal cord, and vertebral arteries (VAs). Therefore, special consideration is necessary for surgery at the CVJ.

Surgical intervention at the CVJ includes resection or decompression in pathological conditions and stabilization. In this review article, the current status of surgical interventions for stabilization of the CVJ is reviewed.

\section{Classification of Surgical Approaches}

Surgical approaches to stabilization methods are classified as either anterior or posterior approaches,

Received December 18, 2015; Accepted January 23, 2016 most of which are posterior approaches. ${ }^{1-3)}$ Anterior odontoid screw fixation is most likely the only established anterior approach. Although the indications are relatively limited, it is an indispensable method for stabilizing an odontoid fracture while maintaining axial rotation. In contrast, there are several posterior approaches, and they can be largely classified as either atlanto-axial fixation or occipito-cervical (O-C) fixation.

\section{Anterior odontoid screw fixation}

Odontoid fractures account for up to $15 \%$ of cervical spine fractures and have an increased incidence in elderly patients. ${ }^{4)} \mathrm{A}$ widely used classification system for odontoid fractures is the Anderson and D'Alonzo classification system. ${ }^{5}$ Type II fractures, in which the fracture line extends through the base of the odontoid process, are common fractures associated with higher nonunion rates of up to $78 \%$ for patients with dens dislocation of $6 \mathrm{~mm}$ or greater. ${ }^{6)}$ Risk factors for nonunion with nonsurgical treatment include the degree of fracture displacement $(>6 \mathrm{~mm}$ ) and angulation ( $>10$ degrees), old age ( $>40-65$ years), posterior odontoid displacement, delayed diagnosis, and communication of the dens base. The established guidelines indicate that patients older than 50 years should undergo surgical treatment. ${ }^{7}$ 
Anterior odontoid screw fixation was initially described in a Japanese orthopedic journal in 1980 by Nakanishi et al. ${ }^{8}$ This paper is not properly acknowledged outside of Japan, and instead, a paper published by Bohler in 1982 has received international recognition for this method. ${ }^{9)}$ The basic concept of this method is to obtain direct osteosynthesis using single or double screws that traverse the fracture line. The greatest advantage of this method over posterior atlanto-axial fixation is the maintenance of atlanto-axial mobility, including axial rotation. ${ }^{10)}$ Other advantages include eliminating the need for bone grafting, less invasiveness, and less soft tissue dissection via a limited anterior cervical exposure. The disadvantages are its limited indications and technical difficulty.

The anterior odontoid screw fixation is indicated when all the following requirements are fulfilled: (1) an acute type II odontoid fracture before fibrous union of the fracture line begins, (2) an intact cruciate ligament, (3) a reducible odontoid fracture, and (4) an accessible anterior cervical oblique trajectory. An appropriate period between injury and surgery is usually less than a month, although Apfelbaum et al. accepts longer periods of up to 6 months. ${ }^{11)}$ An intact cruciate ligament, particularly the transverse ligament, is a necessary condition for applying this technique. Ligament damage can be suspected by soft tissue damage observed on axial magnetic resonance imaging (MRI) or wider displacement of the C1 lateral mass on coronal X-ray or computed tomography (CT). The anterior cervical oblique screw trajectory might not be accessible in patients with a thick thoracic barrel and short neck. Accessibility should be evaluated preoperatively in each patient with a lateral X-ray image. The strict indications of this method limit the number of applicable patients. In a series of surgeries I performed in 20 patients for type II odontoid fractures, anterior odontoid screw fixation was selected in $55 \%$ of the patients, whereas posterior fixation was selected in the remaining patients because they were outside of the above-mentioned indications.

The steps for the surgical procedure can be described briefly (Fig. 1). The patient is placed in a supine position with slight cervical hyperextension to facilitate reduction of the odontoid dislocation and anterior cervical oblique screw trajectory. Biplane fluoroscopic
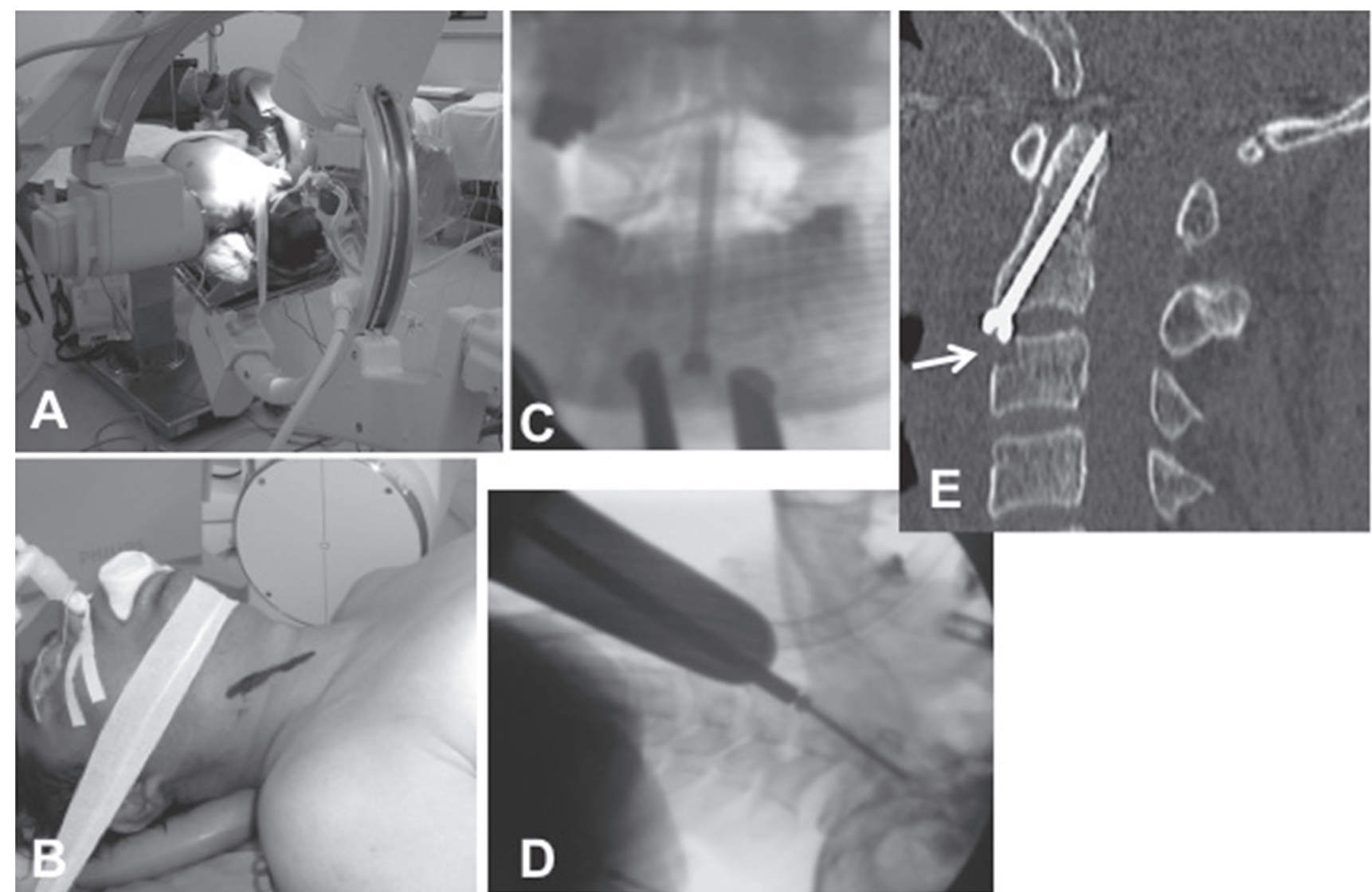

Fig. 1 Anterior odontoid screw fixation. A, B: Intraoperative photographs showing biplane image setting (A) and oblique skin incision (B). C, D: Cervical radiograph, anterior-posterior view (C), lateral view (D). E: Midsagittal computed tomography reconstruction. Arrow shows the drilled region of the superior central portion of the C3 vertebral body. 
guidance is highly recommended for accurate screw placement (Fig. 1A). A transverse skin incision at the C5-6 level or an oblique incision along the sternocleidomastoid muscles is used. Personally, I prefer the oblique incision because it facilitates preparation of the screw insertion at the $\mathrm{C} 2-3$ intervertebral disc space and uses an oblique screw trajectory, which is aimed at the odontoid from the C5-6 level (Fig. 1B). After the incision is made the intervertebral disc at $\mathrm{C} 2 / 3$ is exposed. The superior central portion of the C3 vertebral body is drilled out to facilitate an oblique trajectory for inserting the K-wire with a guide (Fig. 1E). Then, the superior central portion of the C2-3 annulus is removed, and the anterior inferior lip of the C2 body is exposed. A K-wire is advanced with a guide using biplane fluoroscopic guidance through the inferior edge of the $\mathrm{C} 2$ body facing the disc space and traversing the fracture line and apical cortex of the odontoid fracture fragment. The drill bit is then advanced through the C2 body, and the cannulated titanium lag screw is inserted into the tip of the odontoid process, just penetrating the apical cortex. Bicortical purchase is recommended for solid fixation (Fig. 1E).

The average complication rate was estimated at $9.5 \%$. Such complications are predominantly a result of hardware failure, with the most common cause including a screw pullout from the C2 body or breakage of the anterior cortex of C2. ${ }^{11,12)}$ Double anterior odontoid screws have not shown a biomechanical advantage over a single screw. ${ }^{13)}$ Furthermore, double anterior odontoid screw insertion is difficult in patients with a smaller body size, such as individuals of an Asian race.

\section{Posterior atlanto-axial fixation}

Fixation procedures can be classified as interlaminar grafting and wiring methods or screw-rod fixation methods. Interlaminar grafting and wiring methods were first described by Gallie and have been modified by Brooks and others. ${ }^{14-16)}$ These techniques require intact $\mathrm{C} 1-2$ posterior elements, such as the C1 posterior arch and the C2 lamina. Stability can be obtained at the atlanto-axial joints with the graft and cable construct through dorsal wiring of the C1 posterior arch, strut bone graft, and C2 lamina, which serves as a tension band that restricts extension and flexion. However, the ability of this method to restrict axial rotation is inferior. Furthermore, wire loosening, atrophy of grafted bone, and bony erosion at the interface between the wire and bony strut are potential risks for failed bone union. Therefore, these methods include semi-rigid fixation and thus allow limited stabilization of cervical motion. These methods must be supplemented with a rigid, external orthosis until the bone fusion is complete. However, a substantially high rate of failed union has been reported because it is not easy for most patients to wear a rigid external orthosis consistently. ${ }^{17-19)}$ Consequently, more rigid screw-rod fixation methods have become popular and are typically the first choice in most adult patients and even in some children with mature spines. These methods include transarticular screw fixation at the C1-2 and C1 lateral mass and C2 screw and rod fixation.

\section{C1-2 transarticular screw fixation (Magerl's method)}

This method was first described by Magerl and Seeman in $1987 .{ }^{20)}$ The lateral atlanto-axial joints are fixed with screws transarticularly inserted from the back (Fig. 2). This method is usually combined with interlaminar grafting and wiring techniques to reinforce the stability of flexion-extension movements. This is a revolutionary method in arthrodesis
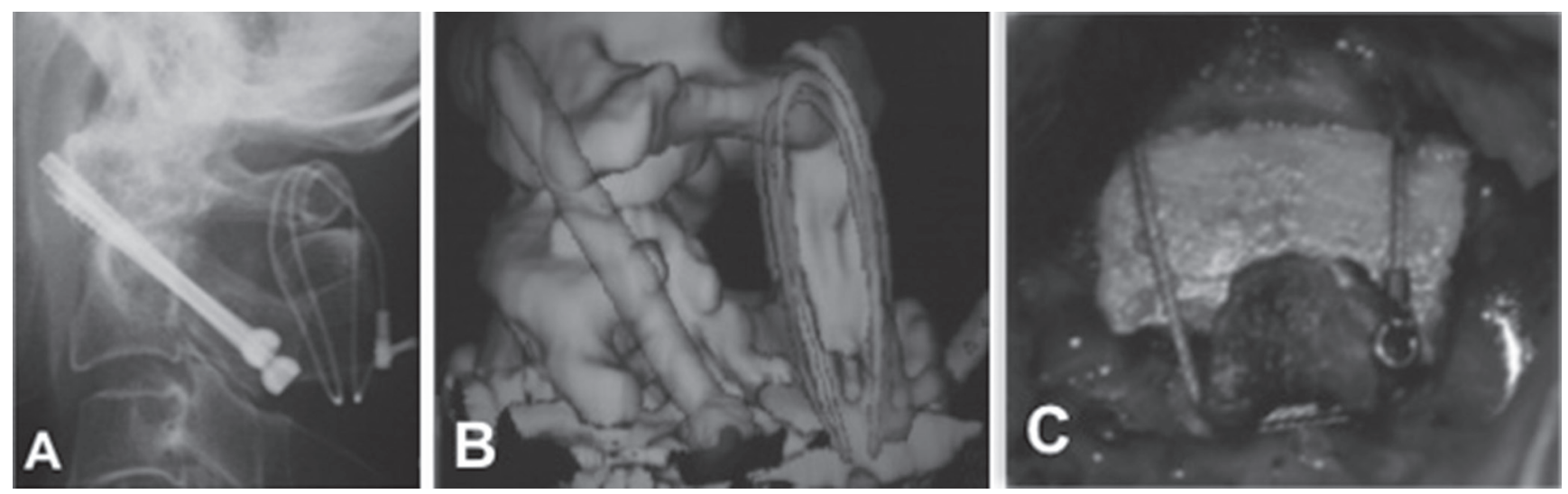

Fig. 2 C1/2 transarticular screw fixation with interlaminar bone grafting and wiring (Magerl's) method. A: Lateral cervical radiograph, B: three-dimensional computed tomography reconstruction, C: intraoperative photograph. 
at the CVJ because it is the first to use screws for a posterior fixation device. This method can achieve immediate rigid fixation with high fusion rates..$^{20,21)}$ However, there are some limitations to this method. The screw placement is technically demanding, and there are substantial risks for vertebral artery (VA) injury. Indications are limited for patients with (1) a reducible AAD, (2) a sufficient volume of the $\mathrm{C} 2$ pedicles or pars interarticularis without a highriding VA, and (3) an accessible posterior cervical oblique screw trajectory.

Transarticular screw placement is technically demanding. Extensive preoperative imaging studies are essential to determine a safe screw trajectory that avoids VA injury. These include plain X-ray films with extension and flexion, CT with sagittal reformatting, and three-dimensional (3D)-CT angiography. The size of the C2 pars interarticularis may limit this approach in up to $20 \%$ of adult patients. ${ }^{22}$ In particular, patients with rheumatoid arthritis (RA) should be carefully evaluated because $70 \%$ of patients in a Japanese population with RA had a high-riding VA. ${ }^{23)}$ In patients with hypolastic or anaplastic VA, screw insertion to the dominant VA should be avoided or performed with extreme caution. It was reported that single C1/2 transarticular screws combined with interlaminar bone graft wiring had good postoperative results and sufficient biomechanical stability. ${ }^{24,25)}$ Use of navigation systems is highly recommended for this method to facilitate preoperative evaluation of indications and proper screw trajectories, in addition to improving intraoperative accuracy and safety.

A brief technical description of this method is presented below. The patients are placed in the prone position, reducing atlanto-axial subluxation under lateral fluoroscopy, and their heads are fixed with a head frame. Reduction of AAD can be achieved by the retracted head position, which also facilitates the screw trajectory. The laminae of C1 through C3 and the articular facets at $\mathrm{C} 1 / 2$ are exposed via a midline skin incision. When navigation is planned preoperatively, the reference frame is installed at the C2 spinous process. First, K-wire is inserted along the screw trajectory via a single long midline skin incision down to the cervicothoracic junction. The K-wire also can be inserted via bilateral stab incisions at the T1 level and passing a guide trocar percutaneously through the two incisions. The typical entry point of the screw at the $\mathrm{C} 2$ inferior fact is a few millimeters superior to the $\mathrm{C} 2-3$ facet joint and a few millimeters lateral to the lamina-lateral mass junction. However, the exact entry point depends on the patient's bony anatomy; therefore, it must be determined for each patient based on the preoperative image. From this entry point, the K-wire is advanced through the C1/2 lateral joints and is aimed at the upper part of the anterior arch of C1 based on the lateral X-ray image and the navigation guidance. The most medial and posterior parts of the isthmus of C2 are recommended for safe screw trajectory in patients with a high-riding VA. ${ }^{26)}$ Once the guide wire is properly inserted through the facet joint, motion between $\mathrm{C} 1$ and $\mathrm{C} 2$ is prevented. The screw length is measured, which is usually $36 \mathrm{~mm}$ to 40 $\mathrm{mm}$. After drilling and tapping, screws are inserted along the K-wire. Finally, bone grafting and wiring are achieved according to the methods described by Gallie, Brooks et al., or others (Fig. 2C).

The VA injury rate is reported to be $4.1 \%$ per patient. ${ }^{27)}$ Cases of suspected vascular injury should be promptly evaluated with angiography immediately after the surgery. Angiographic findings suggesting VA injury include VA dissection with partial or complete occlusion and arteriovenous fistulas. Pulsatile bruit can be audible in patients with arteriovenous fistulas. One of the most serious complications is embolic infarction of the brainstem or cerebellum from a dissected, partially occluded, or recanalized VA. Patients with these conditions should be treated with an appropriate endovascular procedure and/or anticoagulant therapy.

\section{C1 lateral mass and C2 anchor screw fixation method (Goel-Harms method)}

The method of C1 lateral mass screws connecting the C2 anchor screws has recently become popular because of its wide applications and safety (Figs. 3, 4). Goel and Laheri originally described atlanto-axial fixation with C1 lateral mass screws and plates, in 1994. ${ }^{28)}$ In their technique, the $\mathrm{C} 1$ lateral mass screws and the C2 pars screws were fixed via a plate. Therefore, complete exposure of the posterior surface of the lateral atlanto-axial joints by cutting the $\mathrm{C} 2$ nerve root was required to place the plates and screws. In contrast, Harms et al. described in 2000 a rigid C1-2 fixation technique that uses polyaxial anchor screws inserted individually into the C1 lateral mass and C2 pedicle, which were connected via rods. ${ }^{29)}$ The indication of this method was later expanded in 2004 by Wright who reported using translaminar screws for the $\mathrm{C} 2$ anchor instead of C2 pedicle screws. ${ }^{30)}$ Thus, pedicle screws, pars screws, or laminar screws can be used safely for the C2 anchor screw. Therefore, this method will likely be named the Goel-Harms-Wright method.

The advantages of this method over the Magerl's transarticular method are as follows: (1) wider indications, (2) simplicity of each screw trajectory, and (3) feasibility of intraoperative reduction. Almost 

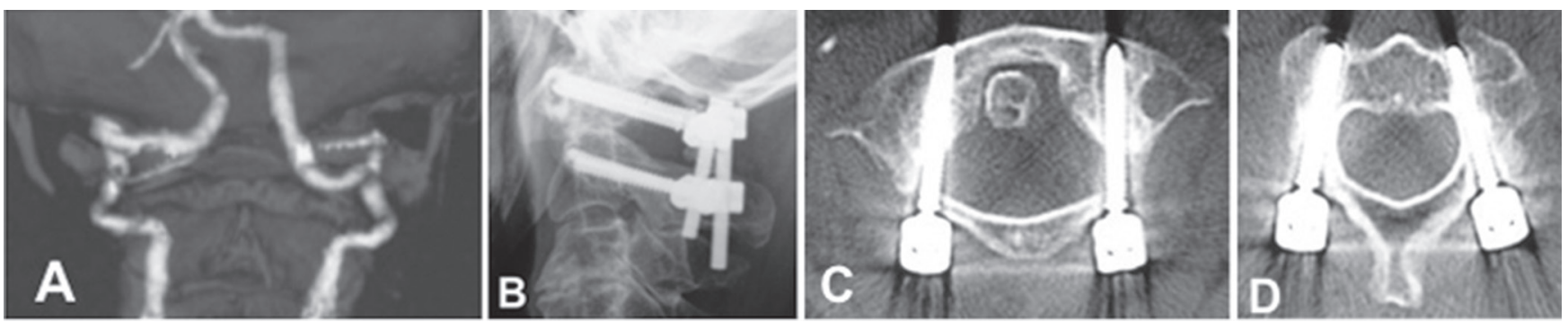

Fig. 3 C1 lateral mass and C2 pedicle screw fixation (Goel-Harms) method. A: preoperative 3D-CT angiography, showing bilateral vertebral artery fenestration; B: lateral cervical radiograph, C, D: axial CT showing the bilateral C1 lateral mass screws (C) and the C2 pedicle screws (D).
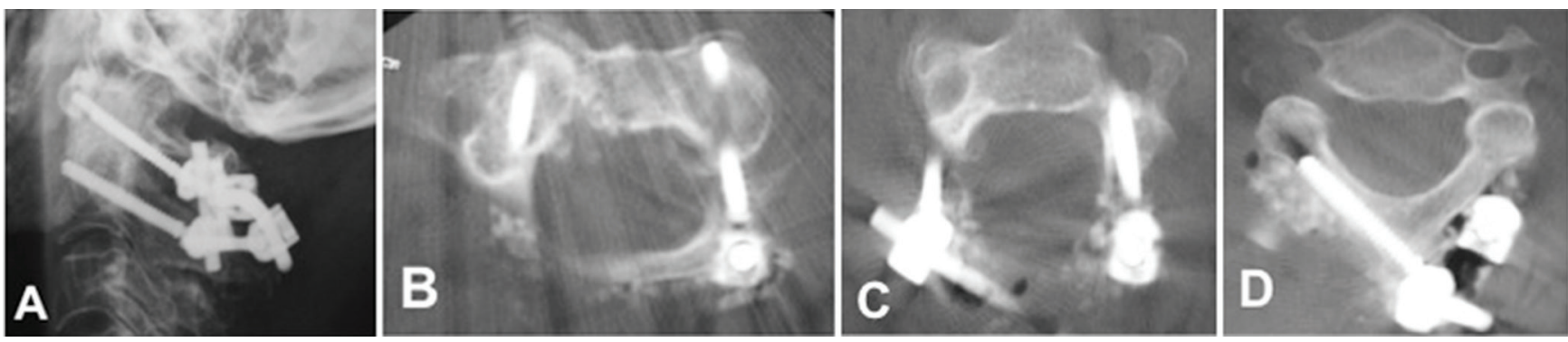

Fig. 4 C1 lateral mass and C2 screw fixation using the translaminar screw (Goel-Harms-Wright method). A-D: Lateral cervical radiograph (A), axial computed tomography showing the bilateral C1 lateral mass screws (B), the C2 pedicle screw (C), and the translaminar screw (D).

all adult patients with atlanto-axial dislocation can be treated with this method. The C1 lateral mass is usually large enough for lateral mass screws in adults. For the $\mathrm{C} 2$ anchor, appropriate screws can be selected from among pedicle, pars articularis, or translaminar screws. Translaminar screws can be used in most patients with few exceptions and can even be used in patients with small pedicles. The screw trajectory for anchor screws is usually more straightforward in the sagittal and axial planes than that of transarticular screws, which have a strong oblique trajectory. Therefore, screw placement is usually simpler. Further reduction of AAD can be achieved between screws at C1 and C2 by using a persuader device.

\section{i. C1 lateral mass screw}

This is the fundamental anchor screw in the C1 lateral mass and C2 anchor screw (Goel-HarmsWright) method (Figs. 3, 4). Technically, there are three variations for screw placement to the C1 lateral mass, such as the Goel-Harms' method, ${ }^{28,29)}$ Tan's method, ${ }^{31)}$ and the notch method. ${ }^{32)}$ The screws are directly inserted into the lateral masses in the Goel-Harms method. In Tan's method, the screw is inserted into the lateral mass via the posterior arch. The C1 posterior arch must be large enough (greater than the screw diameter) to utilize this technique. Risks of VA injury at the VA groove might be higher in patients with small posterior arches. In the notch method, the caudal part of the C1 posterior arch, which often overhangs the lateral mass, is removed to facilitate the screw trajectory and visualization of the lateral mass. The notch method is most often applicable and may be useful in patients who have smaller lateral masses, such as Japanese individuals.

Precise preoperative evaluation of the bony anatomy and the course of the VA can be performed on bone CT and 3D-CT angiography to determine the surgical method and facilitate safe screw placement. This includes the shape and height of the lateral masses; thickness of the $\mathrm{C} 1$ posterior ach; variations in the bone anatomy, such as ponticulus posticus; or an anomalous VA, such as the $1^{\text {st }}$ intersegmental artery or fenestration of the VA (Fig. 3A).

The surgical procedures can be described briefly. The posterior atlanto-axial membrane attached to the $\mathrm{C} 1$ posterior arch is dissected under a microscope from the medial to the lateral side, preserving the epidural venous plexus. Maintaining a subperiosteal plane of dissection is important to avoid venous bleeding. The $\mathrm{C} 1$ lateral mass is exposed by retracting the venous plexus and the $\mathrm{C} 2$ nerve root caudally. When sufficient space for screw insertion 
is obtained, the screw is inserted directly into the lateral mass (Goel-Harms method). The screw entry points are opened with a 2-mm high-speed drill. Then, a pedicle probe is inserted into the lateral mass and aimed at the C1 anterior arch. A hand drill is used when the bone is too hard for probing. The drilled holes are then tapped for screws, and the screws are inserted into the lateral mass. A previous study of implanted screws indicated that screws that obtained bicortical purchase showed greater strength (Fig. 3C). When the C1 posterior arch is overhanging, part of the arch is removed to widen the space available for inserting screws (notch method). If the space available for screw placement is limited by the C2 nerve root, then the nerve root is resected. In the series of 80 lateral mass screw insertions I performed, the notch method was used in $70 \%$, the Goel-Harms method in $20 \%$, and the Tans's method in $10 \%$. The C2 nerve root resection was necessary in $16 \%$ of these procedures to obtain space for screw insertion.

\section{ii. C2 pedicle screw}

The C2 pedicle is defined as the portion of the C2 vertebra that is beneath the superior facet and anteromedial to the transverse foramen. ${ }^{33,34)}$ For the $\mathrm{C} 2$ anchor, the C2 pedicle screw is considered most rigid. Therefore, it is indicated first among the C2 anchor screws. However, an anatomical study reported that the size of the pedicle was less than $3.5 \mathrm{~mm}$ in as many as $20 \%$ of patients, ${ }^{35)}$ and this technique was not applicable in those patients. The size and direction of the pedicle varies widely in each patient; therefore, preoperative evaluation on reconstructed CT is important to determine the indication of this method and the screw trajectory. The use of navigation is also recommended.

First, the C1/2 lateral joints are exposed under a microscope beneath the $\mathrm{C} 2$ nerve root, preserving the surrounding venous plexus. The articular cartilage is curetted and removed to induce facet fusion. Furthermore, bone chips may be inserted into the joint space to facilitate fusion. The medio-superior border of the dorsal pedicle and the ventral direction of the pedicle are identified using a micro-dissector. The standard entry point for the pedicle screw is a few millimeters lateral to the medial border of the pedicle at the upper border of the lamina, but it should be determined in each patient based on preoperative radiographic evaluation. ${ }^{36)}$ The entry point at the posterior cortex is marked with a high-speed drill, and a pedicle probe is inserted along the screw trajectory under fluoroscopic and navigation guidance. The insertion angle is usually $15-25^{\circ}$ medially and in a slightly cephalad direction. The drilled holes are tapped, and the screws are inserted. Bicortical purchase of screws is recommended (Fig. 3D). When the internal carotid artery is located medially, there is a danger of injury from the screw tip.

\section{iii. Translaminar screw}

As mentioned previously, pedicle screws are not indicated in all cases, particularly when the patients have a high-riding VA or a small diameter pedicle. In such cases, translaminar screws should be considered (Fig. 4D). This technique was first reported by Wright in 2004. ${ }^{30}$ Because the diameter of the C2 lamina is usually large enough for $3.5 \mathrm{~mm}$ or $4.0 \mathrm{~mm}$ screws, the translaminar screw can be used as an anchor in most cases. A biomechanical study indicated that the stability of translaminar screws was similar to that of pedicle screws. ${ }^{37)}$ The advantages of this technique include: (1) wider indications, (2) little risk of VA, (3) technical simplicity, and (4) no need of fluoroscopy. In contrast, the disadvantages include: (1) biomechanically inferior to the pedicle screw and (2) difficulty in connection with the C1 lateral mass screw via interposed rods. Postoperative laminar fracture also has been reported.

The diameter of the lamina, the direction and length of the screw, and the best entry point are evaluated on preoperative CT. First, the screw entry point is created at the junction of the $\mathrm{C} 2$ spinous process and lamina with a high-speed drill. Then, a pedicle probe or a hand drill is inserted into the contralateral lamina inside the medullary substance between the two cortices. A small ballprobe is then used to palpate the length of the hole to verify that there are no cortical violations in the spinal canal. A longer screw, usually $28-30 \mathrm{~mm}$, is recommended because of its strength (Fig. 4D). In the series of C1 lateral mass and C2 anchor screw fixations I performed, the pedicle screw was the first choice and the translaminar screw the second. The translaminar screw was used as a C2 anchor in 24 patients, $83 \%$ of the patients had unilateral use and only $17 \%$ had bilateral use.

\section{iv. C2 pars screw}

The C2 pars screw is an anchor screw placed at the pars interarticularis. The $\mathrm{C} 2$ pars is the portion of the C2 vertebra that connects the superior and inferior articular facets. ${ }^{33)}$ However, the definition of the pars interarticularis is ambiguous and often confused with the pedicle in C2 because of its unique morphology compared to other cervical spines. ${ }^{34)}$ Therefore, the pars screw is usually considered a short screw penetrating only to the posterior cortex because it stops just dorsal to the pedicle or VA 
groove. The screw entry point is a few millimeters rostral and lateral to the inferior medial aspect of the C2 inferior facet, and the screw stops short of the joints behind the pedicle. Because the screw length is short (typically $12-18 \mathrm{~mm}$ ), it may be the weakest anchor among the three types of anchor screws. Therefore, the pedicle or the translaminar screw was predominantly indicated in my series.

\section{v. Rod connection and bony fusion}

After the anchor screws are placed at C1 and C2, the two screws are connected via a rod. First, the rod should be cut to the appropriate length. A rod that is too long might damage the occipital bone with movement of the atlanto-occipital joints. Connecting the C1 lateral mass screw and the C2 pedicle or the pars screw are usually achieved without difficulty. However, the connection between the $\mathrm{C} 1$ lateral mass and the translaminar screws is more difficult to achieve because the location of each screw head differs in both the coronal and sagittal planes. Connection is usually performed via a bent rod or with an offset connector (Fig. 4A). Dislocation can be reduced by using a persuader. For anterior dislocation of the atlas over axis, the rod is fixed to the $\mathrm{C} 2$ anchor screw head with a setscrew, keeping a space for reduction between the rod and the C1 lateral mass screw. Then, reduction is performed by pulling back the C1 screw toward the rod position using a persuader device.

Bone implantation is usually performed with an interlaminar strut iliac bone graft. When the C1 posterior arch is defective or weak for reasons including post-decompression or fracture, facet fusion at the $\mathrm{C} 1 / 2$ lateral joint is attempted as described above.

\section{O-C fixation}

O-C fixation is a method for fusing the occipital bone and the cervical spine, which results in severe restriction of head movement after surgery. Therefore, the indication of this method should be restricted to patients who have O-C instability. A significant number of patients with atlanto-axial instability who were not candidates for atlanto-axial fixation underwent $\mathrm{O}-\mathrm{C}$ fixation. This was mainly because of the technical difficulties in C1-2 fixation, such as a high-riding VA and defects of the $\mathrm{C} 1$ posterior arch. Interestingly, the indications for O-C fixation have decreased markedly after the C1 lateral mass-C2 screw-rod fixation method was introduced because C1-2 fixation has become possible in most patients with atlanto-axial instability. At our institute, the ratio of patients undergoing O-C fixation and C1-2 fixation was 3:1 in 38 patients between 1996 and 2003, which was during the era in which the C1/2 transarticular screw (Magerl's) method was commonly used, but this ratio reversed to $1: 3$ in 43 patients between 2007 and 2014, which was during the era in which the Goel-Harms-Wright method was commonly used.

In the late $1980 \mathrm{~s}$, the standard method for performing O-C fixation included a contoured rod and wiring system, such as the Ransford loop. ${ }^{38,39)}$ In this method, a pre-shaped titanium rod is contoured according to the O-C angle. Then, the rod is fixed to the occipital bone using a titanium wire cable passed through the occipital bur holes and to the cervical lamina by sublaminar wiring. This technique provides immediate, semi-rigid fixation of the CVJ. The disadvantage of this technique is an increased susceptibility to axial compression loads producing vertical subsidence. This increased susceptibility can be caused by the rods sliding through the wires, which can result from wire loosening, bone atrophy, or erosion at the interface between the wire and the bone. The techniques of O-C fixation have evolved in the last 20 years, during which the rod and screw systems were introduced.

Rod and screw system: The Olerud Cervical System, which was introduced in 1997, was the first rod and screw system for O-C fixation. ${ }^{40)}$ The contoured rod was connected to the various monoaxial anchor screws at the cervical spine, such as the subaxial lateral mass, transarticular and pedicle screws, the C2 pedicle, C2 translaminar, or C1/2 transarticular screws (Fig. 5). Then, the rod was fixed to the occipital bone with occiput screws. Rigid fixation
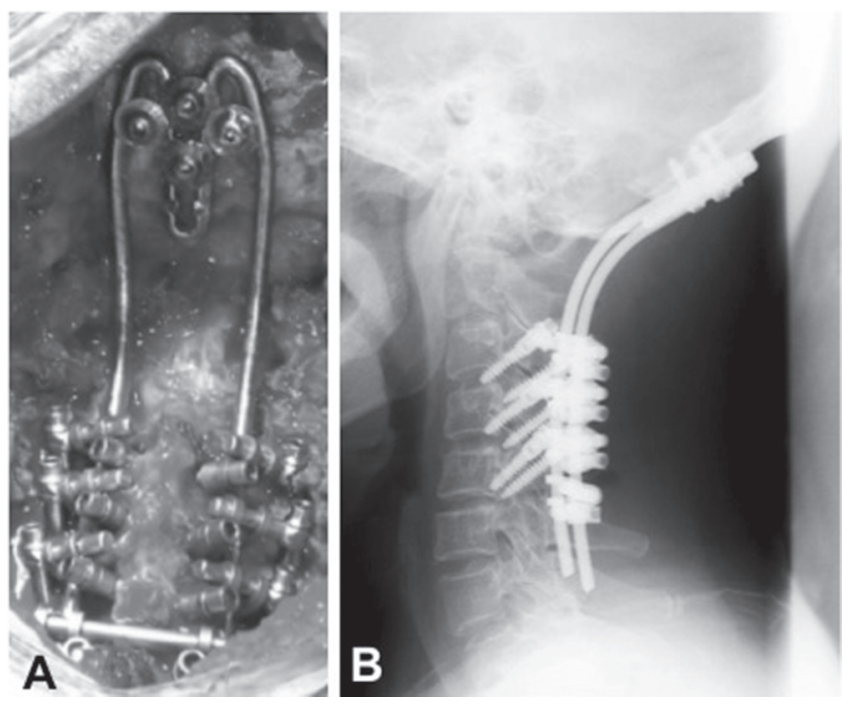

Fig. 5 Occipito-cervical fixation using the monoaxial screw and a rod system (Olerud cervical system). A: Intraoperative photographs showing the rod, screws, and offset connectors, B: lateral cervical radiograph. 
at the CVJ was achieved with this instrumentation system. However, connection of the rod and each monoaxial anchor screw was often so complicated and time consuming that special offset connectors were used (Fig. 5A). Fortunately, new polyaxial screw systems have become available and allow easier connections between the rod and the screw (Figs. 6, 7). ${ }^{41}$ Midline suboccipital screws, which can achieve bicortical purchase, were reported to have the greatest strength. ${ }^{42)}$ The combination of
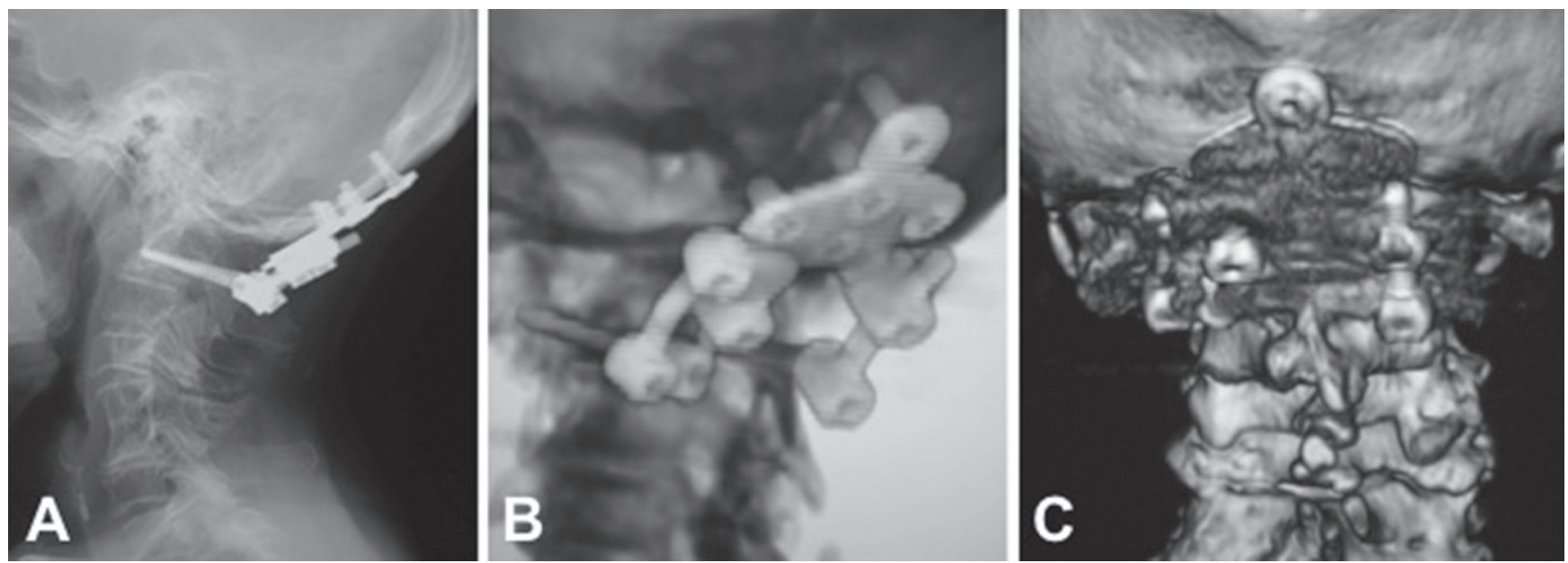

Fig. 6 Occipito-cervical fixation using the polyaxial screws and rod system. A: Lateral cervical radiograph, B: 3D-CT reconstruction oblique view, and C: posterior view showing grafted bone chips around the screws and rods.
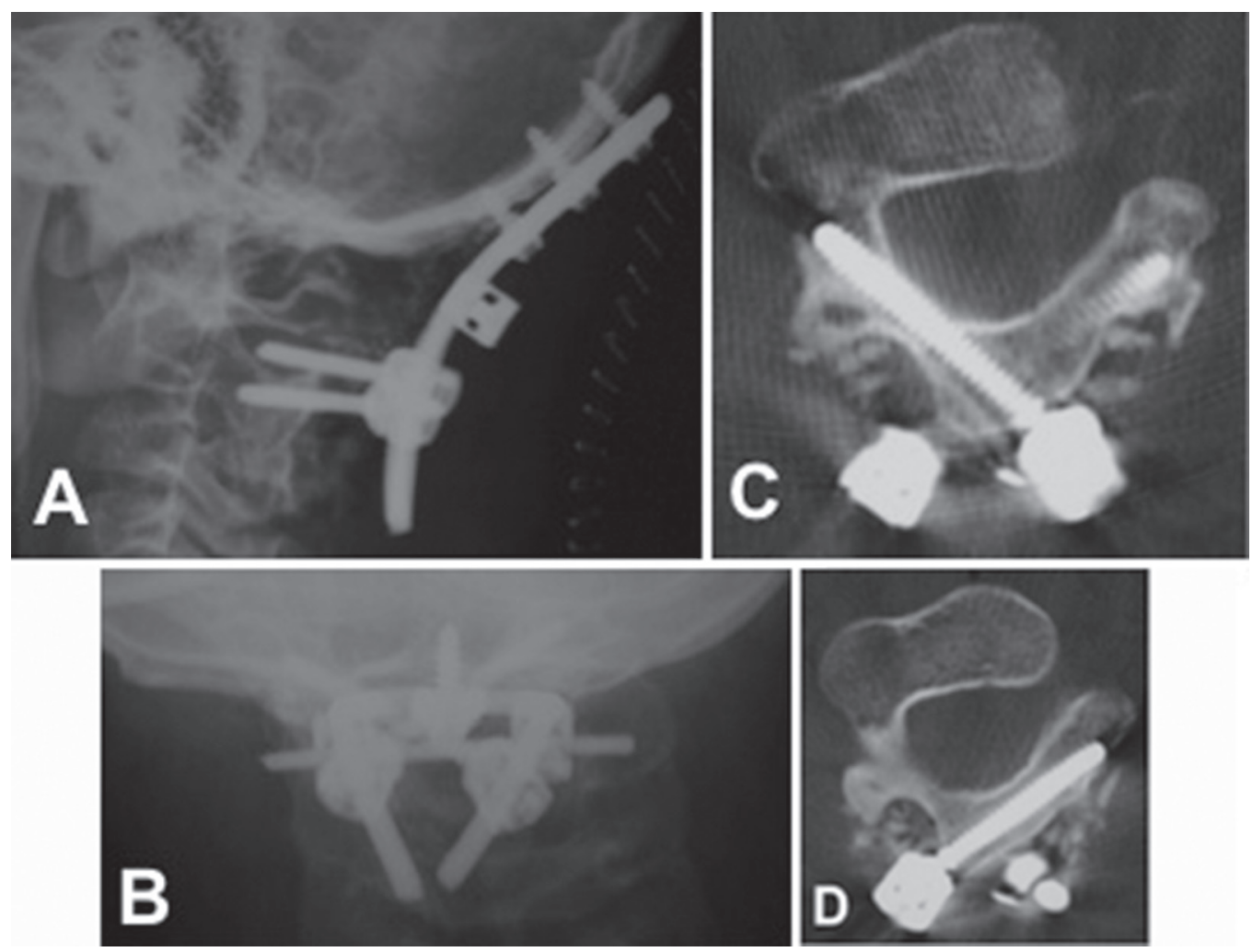

Fig. 7 Occipito-cervical fixation using the polyaxial screw and rod system, using bilateral C2 translaminar screws as the C2 anchor. A: Cervical radiograph lateral view, B: anterior-posterior view. C, D: Axial computed tomography showing bilateral C2 translaminar screws. 
paramedian screws and midline screws is biomechanically stronger for axial rotation. As a result of the introduction of stronger C2 anchor screws, such as the pedicle or the translaminar screws, shorter fixations between the occipital bone and C2 have become possible, except when there is instability below C2/3. ${ }^{43,44)}$

Postoperative dysphagia and/or dyspnea: Postoperative dysphagia and dyspnea are rare complications after O-C fixation. However, they cause serious problems for daily living. Several mechanisms have been proposed for such complications, including changes in cervical alignment, pharyngeal edema, and an enlarged tongue. ${ }^{45-47)}$ Neo's group has clarified one of the mechanisms of postoperative dysphagia and dyspnea after O-C fixation. ${ }^{48,49)}$ The occipitoC2 angle, which is the angle between McGregor's line and the inferior endplate line of $\mathrm{C} 2$, showed a positive correlation with the sagittal diameter of the narrowest oropharyngeal air space, suggesting that fixation with a decreased lordotic occipito-C2 angle induces dysphagia or dyspnea. The narrowest oropharyngeal air space and postoperative dyspnea or dysphagia did not change after a mean follow-up period of 45 months once the O-C2 angle had been established at the O-C fusion. They further indicated that reduction of the anterior atlanto-axial subluxation had negative effects on the oropharyngeal airway space, and therefore, reduction of the anterior AAS might cause postoperative dysphagia or dyspnea, despite maintenance of the O-C2 angle. ${ }^{50)}$ Careful attention should be paid to the sagittal occipito-C2 angle in patients with O-C fixation.

\section{Conclusion}

The surgical approaches for stabilization methods of CVJ are complicated and vary widely. The anterior odontoid screw fixation technique is a useful method for restoring stability after an odontoid fracture while maintaining axial rotation. However, the indications for this technique are relatively limited. The posterior approaches are further classified as atlanto-axial fixation or O-C fixation. Spinal instrumentation using anchor screws and rods has become a popular method and a substitute for previous methods that use bone grafts and wiring because it has greater stability and a higher success rate of fusion. There are a variety of anchor screws available, including C1/2 transarticular, C1 lateral mass, C2 pedicle, and translaminar screws. An appropriate anchor screw should be selected by considering factors such as the technical feasibility, safety, and strength. Shorter fixation has become possible with these stronger anchor screws.

\section{Conflicts of Interest Disclosure}

The author reports no conflicts of interest concerning the materials or methods used in this study or the findings specified in this article. All authors who are members of The Japan Neurosurgical Society (JNS) have registered online Self-reported COI Disclosure Statement Forms through the website for JNS members.

\section{References}

1) Takayasu M, Hara M, Saito K, Yoshida J: Instrumentation for craniovertebral junction lesions. Spinal Surgery 11: 135-142, 1997 (Japanese)

2) Takayasu M: Surgical strategies for the craniocervical junction. Jpn J Neurosurg 22: 427-434, 2013 (Japanese)

3) Ahmed R, Traynelis VC, Menezes AH: Fusions at the craniovertebral junction. Childs Nerv Syst 24: 1209-1224, 2008

4) Clark CR, White AA: Fractures of the dens. A multicenter study. J Bone Joint Surg Am 67: 1340-1348, 1985

5) Anderson LD, D'Alonzo RT: Fractures of the odontoid process of the axis. J Bone Joint Surg Am 56: 1663-1674, 1974

6) Hadley MN, Dickman CA, Browner CM, Sonntag VK: Acute axis fractures: a review of 229 cases. J Neurosurg 71: 642-647, 1989

7) Lennarson PJ, Mostafavi H, Traynelis VC, Walters BC: Management of type II dens fractures: a case-control study. Spine 25: 1234-1237, 2000

8) Nakanishi T, Sasaki T, Takahata T, Aoki Y, Sueyasu M, Uzawa M, Washiya S, Imanaka K: Internal fixation of the odontoid fracture. Cent Jpn J Orthop Traumatic Surg 23: 399-406, 1980 (Japanese)

9) Böhler J: Anterior stabilization for acute fractures and non-unions of the dens. J Bone Joint Surg Am 64: 18-27, 1982

10) Jeanneret B, Vernet O, Frei S, Magerl F: Atlantoaxial mobility after screw fixation of the odontoid: a computed tomographic study. J Spinal Disord 4: 203-211, 1991

11) Apfelbaum RI, Lonser RR, Veres R, Casey A: Direct anterior screw fixation for recent and remote odontoid fractures. J Neurosurg 93(2 Suppl): 227-236, 2000

12) Subach BR, Morone MA, Haid RW Jr, McLaughlin MR, Rodts GR, Comey CH: Management of acute odontoid fractures with single-screw anterior fixation. Neurosurgery 45: 812-819; discussion 819-820, 1999

13) Sasso R, Doherty BJ, Crawford MJ, Heggeness $\mathrm{MH}$ : Biomechanics of odontoid fracture fixation. Comparison of the one- and two-screw technique. Spine 18: 1950-1953, 1993

14) Gallie WE: Fractures and dislocations of the cervical spine. Am J Surg 46: 495-499, 1939

15) Brooks AL, Jenkins EB: Atlanto-axial arthrodesis by the wedge compression method. J Bone Joint Surg Am 60: 279-284, 1978 
16) Dickman CA, Sonntag VK, Papadopoulos SM, Hadley MN: The interspinous method of posterior atlantoaxial arthrodesis. J Neurosurg 74: 190-198, 1991

17) Dickman CA, Crawford NR, Paramore CG: Biomechanical characteristics of C1-2 cable fixations. $J$ Neurosurg 85: 316-322, 1996

18) Naderi S, Crawford NR, Song GS, Sonntag VK, Dickman CA: Biomechanical comparison of C1-C2 posterior fixations. Cable, graft, and screw combinations. Spine (Phila Pa 1976) 23: 1946-1955; discussion 1955-1956, 1998

19) Mitchell TC, Sadasivan KK, Ogden AL, Mayeux RH, Mukherjee DP, Albright JA: Biomechanical study of atlantoaxial arthrodesis: transarticular screw fixation versus modified Brooks posterior wiring. J Orthop Trauma 13: 483-489, 1999

20) Magerl F, Seeman PS: Stable posterior fusion of the atlas and axis by transarticular screw fixation, in Kehr P, Weider A (eds): Cervical Spine I. Wien, Spinger-Verlag, 1987, pp 322-327

21) Marcotte P, Dickman CA, Sonntag VK, Karahalios DG, Drabier J: Posterior atlantoaxial facet screw fixation. J Neurosurg 79: 234-237, 1993

22) Paramore CG, Dickman CA, Sonntag VK: The anatomical suitability of the C1-2 complex for transarticular screw fixation. J Neurosurg 85: 221-224, 1996

23) Miyata M, Neo M, Ito H, Yoshida M, Miyaki K, Fujibayashi S, Nakayama T, Nakamura T: Is rheumatoid arthritis a risk factor for a high-riding vertebral artery? Spine 33: 2007-2011, 2008

24) Song GS, Theodore N, Dickman CA, Sonntag VK: Unilateral posterior atlantoaxial transarticular screw fixation. J Neurosurg 87: 851-855, 1997

25) Nichols LA, Mukherjee DP, Ogden AL, Sadasivan KK, Albright JA: A biomechanical study of unilateral posterior atlantoaxial transarticular screw fixation. J Long Term Eff Med Implants 15: 33-38, 2005

26) Neo M, Matsushita M, Iwashita Y, Yasuda T, Sakamoto T, Nakamura T: Atlantoaxial transarticular screw fixation for a high-riding vertebral artery. Spine 28: 666-670, 2003

27) Wright NM, Lauryssen C: Vertebral artery injury in C1-2 transarticular screw fixation: results of a survey of the AANS/CNS section on disorders of the spine and peripheral nerves. American Association of Neurological Surgeons/Congress of Neurological Surgeons. J Neurosurg 88: 634-640, 1998

28) Goel A, Laheri V: Plate and screw fixation for atlanto-axial subluxation. Acta Neurochir (Wien) 129: 47-53, 1994

29) Harms J, Melcher RP: Posterior C1-C2 fusion with polyaxial screw and rod fixation. Spine 26: 24672471, 2001

30) Wright NM: Posterior C2 fixation using bilateral, crossing C2 laminar screws: case series and technical note. J Spinal Disord Tech 17: 158-162, 2004

31) Tan M, Wang H, Wang Y, Zhang G, Yi P, Li Z, Wei $\mathrm{H}$, Yang F: Morphometric evaluation of screw fixation in atlas via posterior arch and lateral mass. Spine 28: 888-895, 2003

32) Lee MJ, Cassinelli E, Riew KD: The feasibility of inserting atlas lateral mass screws via the posterior arch. Spine 31: 2798-2801, 2006

33) Ebraheim NA, Fow J, Xu R, Yeasting RA: The location of the pedicle and pars interarticularis in the axis. Spine 26: E34-E37, 2001

34) Mandel IM, Kambach BJ, Petersilge CA, Johnstone B, Yoo JU: Morphologic considerations of C2 isthmus dimensions for the placement of transarticular screws. Spine 25: 1542-1547, 2000

35) Igarashi T, Kikuchi S, Sato K, Kayama S, Otani K: Anatomic study of the axis for surgical planning of transarticular screw fixation. Clin Orthop Relat Res 162-166, 2003

36) Abumi K, Kaneda K: Pedicle screw fixation for nontraumatic lesions of the cervical spine. Spine 22: 1853-1863, 1997

37) Gorek J, Acaroglu E, Berven S, Yousef A, Puttlitz CM: Constructs incorporating intralaminar C2 screws provide rigid stability for atlantoaxial fixation. Spine 30: 1513-1518, 2005

38) Ransford AO, Crockard HA, Pozo JL, Thomas NP, Nelson IW: Craniocervical instability treated by contoured loop fixation. J Bone Joint Surg Br 68: 173-177, 1986

39) Menezes AH: Dorsal occipitocervical fusion: rod and wiring techniques, in Kim DM, Vaccaro AR, Fessler RG (eds): Spinal Instrumentation: Surgical Techniques. New York, Thieme Medical Publishers, 2005, pp 14-19

40) Olerud C, Larsson BE, Rodriguez M: Subaxial cervical spine subluxation in rheumatoid arthritis. A retrospective analysis of 16 operated patients after 1-5 years. Acta Orthop Scand 68: 109-115, 1997

41) Bhatia R, Desouza RM, Bull J, Casey AT: Rigid occipitocervical fixation: indications, outcomes, and complications in the modern era. J Neurosurg Spine 18: 333-339, 2013

42) Haher TR, Yeung AW, Caruso SA, Merola AA, Shin T, Zipnick RI, Gorup JM, Bono C: Occipital screw pullout strength. A biomechanical investigation of occipital morphology. Spine 24: 5-9, 1999

43) Abumi K, Takada T, Shono Y, Kaneda K, Fujiya M: Posterior occipitocervical reconstruction using cervical pedicle screws and plate-rod systems. Spine 24: 1425-1434, 1999

44) Pan J, Huang D, Hao D, Zhao Y, He B, Wu Q, Li H, Ge C: Occipitocervical fusion: fix to C2 or C3? Clin Neurol Neurosurg 127: 134-139, 2014

45) Meakem TD, Meakem TJ, Rappaport W: Airway compromise from prevertebral soft tissue swelling during placement of halo-traction for cervical spine injury. Anesthesiology 73: 775-776, 1990

46) Dark A, Armstrong T: Severe postoperative laryngeal oedema causing total airway obstruction immediately on extubation. Br J Anaesth 82: 644-646, 1999

47) Lee YH, Hsieh PF, Huang HH, Chan KC: Upper airway obstruction after cervical spine fusion 
surgery: role of cervical fixation angle. Acta Anaesthesiol Taiwan 46: 134-137, 2008

48) Yoshida M, Neo M, Fujibayashi S, Nakamura T: Upper-airway obstruction after short posterior occipitocervical fusion in a flexed position. Spine (Phila Pa 1976) 32: E267-E270, 2007

49) Izeki M, Neo M, Takemoto M, Fujibayashi S, Ito H, Nagai K, Matsuda S: The O-C2 angle established at occipito-cervical fusion dictates the patient's destiny in terms of postoperative dyspnea and/or dysphagia. Eur Spine J 23: 328-336, 2014
50) Izeki M, Neo M, Ito H, Nagai K, Ishizaki T, Okamoto T, Fujibayashi S, Takemoto M, Yoshitomi H, Aoyama T, Matsuda S: Reduction of atlantoaxial subluxation causes airway stenosis. Spine 38: E513-E520, 2013

Address reprint requests to: Masakazu Takayasu, MD, Department of Neurological Surgery, Aichi Medical University School of Medicine, 21 Karimata, Yazako, Nagakute-cho, Aichi-gun, Aichi 480-1195, Japan. e-mail: mtakayas@aichi-med-u.ac.jp 